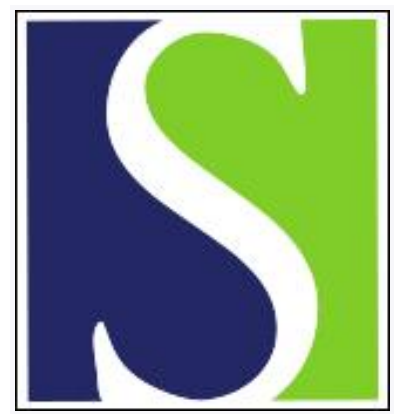

Scand J Work Environ Health 2015;41(2):124-139

https://doi.org/10.5271/sjweh.3476

Published online: 31 Dec 2014, Issue date: 01 Mar 2015

Occupational physical activity and 20 -year incidence of acute myocardial infarction: results from the Kuopio Ischemic Heart Disease Risk Factor Study

by Krause N, Brand RJ, Arah OA, Kauhanen J

This study overcomes several methodological problems of an inconsistent literature and provides evidence for a detrimental role of occupational physical activity on cardiovascular health for men with and without baseline ischemic heart disease. The study also demonstrates that choice of exposure measure and analytic strategy can change direction and size of estimated effects, possibly explaining known inconsistencies in the literature.

Affiliation: UCLA Fielding School of Public Health, 650 Charles E. Young Dr. South, 56-071 CHS, Box 961772, Los Angeles CA 90095-1772, USA. niklaskrause@ucla.edu

Refers to the following texts of the Journal: $2000 ; 26(3): 227-236$

2002;28(1):25-32 2007;33(6):405-424 1989;15(3):165-179

2010;36(5):366-372 2010;36(5):349-355 2010;36(6):466-472

$2015 ; 41(2): 140-152$

The following articles refer to this text: $2015 ; 41(2): 140-152$;

2016;42(4):291-298; 2019;45(3):267-279; 2020;46(3):268-277;

2022;48(2):86-98; 2023;49(3):231-244

Key terms: acute myocardial infarction; cardiorespiratory fitness; cardiovascular disease; coronary heart disease; energy expenditure; Kuopio Ischemic Heart Disease Risk Factor Study; occupational physical activity; physical activity; physical workload; prospective study; relative aerobic strain; relative aerobic workload; relative oxygen uptake reserve; risk factor

This article in PubMed: www.ncbi.nlm.nih.gov/pubmed/25599524

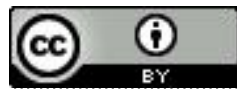




\title{
Occupational physical activity and 20-year incidence of acute myocardial infarction: results from the Kuopio Ischemic Heart Disease Risk Factor Study
}

\author{
by Niklas Krause, MD, MPH, PhD, ${ }^{1}$ Richard J Brand, PhD, ${ }^{2}$ Onyebuchi A Arah, MD, MSc, DSc, MPH, \\ $P h D,{ }^{3}$ Jussi Kauhanen, $M D, P h D^{4}$
}

\begin{abstract}
Krause N, Brand RJ, Arah OA, Kauhanen J. Occupational physical activity and 20-year incidence of acute myocardial infarction: results from the Kuopio Ischemic Heart Disease Risk Factor Study. Scand J Work Environ Health. 2015;41(2):124-139. doi:10.5271/sjweh.3476
\end{abstract} Objectives This study aimed to assess the effects of physically demanding work - measured as energy expen-
diture (EE) during occupational physical activities (OPA) - on risk of acute myocardial infarction (AMI) among
men with and without preexisting ischemic heart disease (IHD).

Methods The 20-year prospective study examined 1891 middle-aged working men using absolute (kcal/day) and relative (relative aerobic strain and percent oxygen uptake reserve) measures of EE. Linear and quadratic hazard models were explored in Cox regression analyses adjusting for 19 potential confounders and considering interactions with baseline IHD.

Results Relative EE measures were positively associated with 20-year incidence of AMI in linear and quadratic hazard models and interacted with IHD. Each 10\% increase of relative aerobic strain increased AMI risk by $18 \%$ among men without IHD [hazard ratio (HR) $1.18,95 \%$ confidence interval $(95 \%$ CI) $1.08-1.28, \mathrm{P}=0.001$ ] and by $8 \%$ among men with IHD (HR 1.08, $95 \%$ CI $0.98-1.20, \mathrm{P}=0.129$ ) in fully adjusted linear models. Results for quadratic models and percent oxygen uptake reserve were similar. Absolute EE did not predict AMI. Age, baseline IHD, systolic blood pressure, anti-hypertensive medication, body mass index, blood glucose, low-density lipoprotein cholesterol, cholesterol-lowering medication, mental stress, and smoking were independently associated with AMI, but not income, social support, alcohol, or conditioning leisure-time physical activity.

Conclusions In contrast to absolute EE, relative workload measures that take individual fitness into account were positively associated with AMI incidence among men without IHD. For men with IHD, associations were also positive but weaker possibly due to healthy worker selection effects. These findings provide evidence for a positive association between OPA and AMI among men.

Key terms cardiovascular disease; cardiorespiratory fitness; coronary heart disease; energy expenditure; physical workload; prospective study; relative aerobic strain; relative aerobic workload; relative oxygen uptake reserve; risk factor.

\begin{abstract}
Although manual work in developed economies has become less strenuous in many occupations, other occupations have seen an increase in work intensity. Ageing generations may still carry the effects of high workrelated physical load from past decades, and globally a large proportion of the world population is still engaged in hard physical labor. In the United States, about 31 million persons or $23 \%$ of the working population in
\end{abstract}

2000 were engaged in high levels of occupational physical activity (OPA) (1), and, in 2009, 6.5 million or $35 \%$ of workers $\geq 58$ years had physically demanding jobs (2).

In contrast to leisure-time physical activity (LTPA), little is known about cardiovascular disease (CVD) and the benefits and risks associated with OPA. Most epidemiological studies to date have either failed to differentiate between LTPA and OPA or excluded OPA from their

1 University of California, Los Angeles (UCLA), Fielding School of Public Health, Department of Environmental Health Sciences and Department of Epidemiology, Los Angeles, CA, USA

2 University of California San Francisco (UCSF), Department of Epidemiology and Biostatistics, San Francisco, CA, USA.

3 University of California, Los Angeles (UCLA), Fielding School of Public Health, Department of Epidemiology, Los Angeles, CA, USA.

4 University of Eastern Finland (UEF), Institute of Public Health and Clinical Nutrition, Kuopio, Finland.

Correspondence to: Niklas Krause, UCLA Fielding School of Public Health, 650 Charles E. Young Dr. South, 56-071 CHS, Box 961772 , Los Angeles CA 90095-1772, USA. [E-mail: niklaskrause@ucla.edu] 
analyses altogether (3-6). It is important to examine separately physical activity at and outside work. OPA may not have the health promoting characteristics that are typical for most LTPA.

While the beneficial effects of LTPA on the circulatory system are relatively well established (7), the literature on the health effects of OPA remains inconsistent (8). Higher levels of OPA were associated with a reduced risk of CVD in some prospective population-based studies (9-15) but not others $(10,13,16-21)$ or were associated with an increased CVD risk (22-28) and, in one study, depending on level of fitness (29). A few studies showed differential effects, with LTPA being protective and OPA having no effect $(20,30)$, LTPA having an effect only among persons with low levels of OPA (14), or LTPA constituting a CVD risk (23), especially among persons with high levels of OPA indicating an interaction between OPA and LTPA (28). One recent study found beneficial effects for OPA and LTPA among men, detrimental effects for OPA and no effects for LTPA among women, and detrimental effects for heavy occupational lifting among males with low OPA (31). A meta-analysis of 21 prospective studies published between 1980-2010 concluded that both LTPA and moderate levels of OPA were beneficial for cardiovascular health (7). An updated meta-analysis of 23 prospective cohort studies published in 2011, 2012, and the first quarter of 2013 concluded that these newer studies show that moderate and high levels of OPA are associated with an increased CVD risk (32).

Most studies used only crude categorical measures of OPA. Among the few studies that used a continuous measure of energy expenditure (EE) only one adjusted for individual aerobic fitness that determines the actual cardiovascular load [relative aerobic strain (RAS) also known as relative aerobic workload] in meeting the physical demands of work in terms of the energy expended in performing the work (26). In addition, only three studies adjusted for psychosocial job factors $(25,26,28)$ although job stress has been found to be an important risk factor for CVD in several studies (33-37) and could confound associations between OPA and CVD. Further, one cohort study found strong interactions between OPA and baseline ischemic heart disease (IHD) $(25,26)$, however, no other cohort study investigated this possibility. Such limitations may be responsible for the inconsistent findings in the literature.

The current study was designed to address these methodological issues by (i) using a validated interview instrument to accurately assess OPA at baseline, (ii) using continuous exposure measures, (iii) using relative measures of EE [RAS and percent oxygen uptake reserve $\left(\mathrm{VO}_{2 \mathrm{res}}\right)$ ] taking individual cardiorespiratory fitness into account, and (iv) adjusting for virtually all known biological, behavioral, and psychosocial risk factors for CVD. In addition, this study investigates possible interactions between OPA and pre-existing IHD and investigates the impact of alternative model specifications on the results.

\section{Methods}

\section{Study population}

Subjects were participants in the prospective Kuopio IHD Risk Factor Study, an age-stratified population-based $30 \%$ random sample of Eastern Finnish men, residing in the city of Kuopio or its surrounding rural communities. Details of the study population have been published elsewhere $(38,39)$. Of 3433 eligible men aged 42, 48, 54, or 60 years, 198 could not be included because of death, serious disease, or migration away from the area. Of the remaining eligible candidates, $2682(82.9 \%)$ agreed to participate and underwent baseline examinations between March 1984 and December 1989. Repeat examinations for selected measures were conducted after 4 and 11 years; however, in this study this information was only used in a few instances for substituting missing baseline values in the large baseline sample. Only baseline information was available for relative measures of $\mathrm{EE}$ at work used in this study. Participants who were not working at baseline or in the 12 months prior $(\mathrm{N}=791)$ were excluded. The final study sample included 1891 participants with complete information on all key predictor and outcome variables and a set of 19 covariates that were pre-determined in an earlier study on OPA and progression of carotid atherosclerosis (26).

\section{Assessment of cardiovascular health at baseline}

At baseline, all participants completed extensive questionnaire surveys, were interviewed about their work history, and underwent a comprehensive medical examination including several laboratory tests as described previously (40). Participants were considered to have IHD at baseline if they had a history of myocardial infarction or angina pectoris, currently used anti-angina medication, or had positive findings of angina from the London School of Hygiene cardiovascular questionnaire (41). In this paper, we use this operationalization and the term IHD to define cardiovascular health at baseline only. Although the term IHD in general refers to the same subgroup of CVD as the term "coronary heart disease (CHD)," we use the latter term (CHD) only for first incident CHD during follow-up.

Assessment of incidence of acute myocardial infarction

Participants were followed through 4- and 11-year repeat medical examinations and questionnaire and 
interview surveys including information on past and current CVD. However, in this study first incident AMI was ascertained through record linkage with national hospitalization discharge and death registries including the national AMI register established under the World Health Organizations "Monitoring of Trends and Determinants of Cardiovascular Diseases (MONICA)" project (42). Hospital discharge diagnoses were also checked against other hospital records, lab results, and electrocardiograms by a university-based cardiologist for this study. Follow-up was censored at 31 December 2011 or date of death, whichever occurred first. Follow-up time ranged from 0.01 to 27.76 years (mean 19.56 years).

\section{Assessment of occupational physical activity}

Trained interviewers administered an OPA interview at baseline to men who had worked at least some time in the past 12 months. The interview addressed a typical workday. Subjects were asked, with an accuracy of 15 minutes, how long they had performed the following activities at work: sitting, standing, walking on level ground, walking on uneven ground, climbing stairs, or any other activities. The 12 months test-retest correlations for the OPA interview was found to be 0.69 indicating good reliability of the instrument (43). Lifetime job stability among people living in the Kuopio region is relatively high (44) reducing the probability of misclassification of work activities between follow-up examinations.

A self-administered baseline questionnaire provided information on work status (working full time, working part time, unemployed, retired, not working for other reason). Those not currently working were asked about the year when an unemployment or retirement period began, the number of days worked per week in the last job, and number of hours worked per day. For those working, workdays per week, the number of hours and minutes worked per day, and the number of days they missed work due to illness during the past 12 months were assessed. Occupation was also assessed and 3-digit coded according to the Finnish Classification of Occupations of Tilastokeskus (Center of Statistics of Finland).

\section{Absolute and relative measures of energy expenditure at work}

Absolute EE at work (in kcal/day) was assessed from baseline interview data on time spent in various activities at work during a typical workday and reference data on the energy requirements ( $\mathrm{kcal} / \mathrm{kg} /$ hour) of these activities. Worker weight was measured at the baseline medical examination. Additional information on cardiorespiratory fitness [maximal oxygen uptake $\left(\mathrm{VO}_{2 \max }\right)$ ] was used to create two relative measures of EE that take workers' individual aerobic capacity into account and measure their relative aerobic workload: RAS and $\mathrm{VO}_{2 \text { res }}$. Other basic data gathered included the number of days and hours typically worked per week.

\section{Absolute energy expenditure per typical workday}

EE per typical workday reflects the sum of the durations and intensities of each OPA. The duration (hours/ typical day) of different physical activities at work was assessed by an occupational interview. The energy requirements of these activities were estimated as multiples of the baseline metabolic rate (MET) in kilocalories $/ \mathrm{kg} /$ hour of an average male with values of 1.6 for work while sitting, 2.4 for standing, 3.3 for walking on level ground, 4.9 for walking on uneven ground, 7.3 for climbing stairs and a mean value of 3.9 for other non-specified activities based on previously published data $(45,46)$. EE in kcal for each reported activity is calculated by multiplying the duration (hours per day) by the respective intensity (MET) and body weight $(\mathrm{kg})$ of the individual. The sum of these estimates gives the EE measured in kcal per typical workday.

Although absolute EE was reassessed at 4- and 11-year follow-up, this investigation uses only baseline values because (i) incomplete follow-up data would otherwise reduce the sample size, (ii) previous analyses showed that the use of cumulative measures of EE resulted in only relatively small increases in predictive power compared to simple baseline measures of $\mathrm{EE}$ (26), and (iii) cardiorespiratory fitness, an important codeterminant of the health impact of OPA, was only available at baseline.

\section{Cardiorespiratory fitness}

Cardiorespiratory fitness (also known as aerobic capacity or $\mathrm{VO}_{2 \max }$ ) was assessed by a maximal but symptomlimited exercise test on an electrically braked ergometer as explained in detail elsewhere $(39,47,48)$. Oxygen consumption was measured using respiratory gas exchange analysis. $\mathrm{VO}_{2 \max }$ was defined as the highest value or plateau in oxygen uptake and was standardized by body weight and measured as $\mathrm{ml} \mathrm{O}_{2}$ per $\mathrm{kg}$ per minute during maximal symptom-limited bicycle ergometry (47).

\section{Relative aerobic strain at baseline}

RAS $\left(\% \mathrm{VO}_{2 \max }\right)$ is a relative EE measure that expresses the physical demands of work (in terms of energy needed to perform the job) as a percentage of the individual worker's aerobic cardiorespiratory fitness or maximal work capacity (49). RAS is a measure of relative aerobic workload that has traditionally been used to define recommended maximum levels of aerobic work demands. 


\section{Percent oxygen uptake reserve at baseline}

The $\% \mathrm{VO}_{2 \text { res }}$ is an alternative relative EE measure that expresses the physical demands of work in relation to the individual workers' aerobic cardiorespiratory fitness or maximal work capacity as the percentage of oxygen uptake reserve $\left(\% \mathrm{VO}_{2 \mathrm{res}}\right)(50)$. While RAS is based on the total EE at work including the energetic cost of metabolic rate for both rest and work activity, $\% \mathrm{VO}_{2 \text { res }}$ is based on the EE associated with the work activity only and measured as $\% \mathrm{VO}_{2 \mathrm{res}}=\left(\mathrm{VO}_{2 \text { work }}-3.5\right) /\left(\mathrm{VO}_{2 \max }-3.5\right) \times 100 \%$ because the resting EE is $1 \mathrm{MET}=3.5 \mathrm{ml} \mathrm{O} / \mathrm{kg}$ per minute $(50,51)$. In our study, $\mathrm{VO}_{2 \text { work }}$ was determined by calculating the weighted average of MET during work activities based on the occupational interview multiplied by $3.5 \mathrm{ml} / \mathrm{kg}$ per minute. Recently, $\% \mathrm{VO}_{2 \text { res }}$ has been suggested as the preferred measure of relative EE for use in job analyses and epidemiological field studies because it allows for more adequate comparisons than $\% \mathrm{VO}_{2 \max }$ when EE varies greatly in the study population. A further advantage of this measure is the fact that, in contrast to $\% \mathrm{VO}_{2 \max }, \% \mathrm{VO}_{2 \text { res }}$ corresponds directly to percent heart rate reserve that can be measured more easily in the field than $\% \mathrm{VO}_{2 \text { res }}$ itself (50).

\section{Assessment of covariates}

Covariates (listed in table 1) were assessed at baseline and 4 and 11 years. For this analyses, repeat measures were only used in a few cases for substituting baseline values. Details of the measurement of these variables have been described previously $(40,52)$. In the following, we give a brief summary of the measurement of key covariates.

Blood pressure was measured with a random-zero sphygmanometer after a supine rest of five minutes. Three measurements were then taken while the subject was still supine, one while standing, and two while sitting, in that order. The average of these six measurements was used in our analyses. BMI was defined as weight in kilograms divided by height in meter squared. Use of cholesterol and blood-pressure-lowering medications was assessed by questionnaire. Alcohol consumption in grams per week during the past 12 months was assessed with a structured quantity-frequency method using the Nordic Alcohol Consumption Inventory (53). Cigarette use was a four-level categorical variable: never smoked, former smoker, irregular smoker, and current regular smoker. Conditioning LTPA, in hours per year, was measured using a modified version of the Minnesota LTPA questionnaire (54) that included the 16 most common LTPA of middle-aged Finnish men (45). Respondents were asked to estimate the duration, frequency, and intensity of each of 16 activities performed for each of the 12 previous months. Socioeconomic status (SES) was measured by personal income in Finn- ish marks, social support at work from coworkers and supervisors was measured by several standard items, stress from work deadlines was measured by one item, and a 10 -item mental strain index measured job stress as described previously (40).

\section{Statistical analysis}

The baseline characteristics of men with and without baseline IHD were compared using t-tests for continuous and $\mathrm{chi}^{2}$ tests for categorical variables. Incidence rates were calculated using person-time data.

Associations between OPA and CVD outcomes were assessed with Cox proportional hazard models (55) adjusting for all covariates listed in table 1 that were considered potential confounders, with the exception of cardiorespiratory fitness which is already an integral component of the two relative EE measures. The list is identical to the covariates used in a previous study of OPA and 11-year progression of carotid atherosclerosis to facilitate direct comparisons (26). All continuous variables were centered at the mean, making the average rather than a zero value the reference for presented hazard ratios. For the few remaining categorical variables, the low-risk category was chosen as reference. Each OPA measure was evaluated in separate models with incremental adjustment for potential confounders and inclusion of interaction terms. After examining categorized measures of OPA for non-linear trends, we explored both linear hazard and quadratic OPA hazard models (the latter including both a linear and quadratic exposure term) using maximum likelihood ratio test statistics to assess fit. We present hazard ratios (HR) and $95 \%$ confidence intervals $(95 \% \mathrm{CI})$ for both hazard models in separate tables 2 and 3. Models were incrementally adjusted for age, for all other covariates listed in table 1 , for baseline IHD, and OPA $\times$ IHD interaction terms. We also computed separate association measures for men with and without baseline IHD.

The product (interaction) term in our interaction model serves to evaluate a "statistical" interaction in the sense of departure from multiplicativity in the joint effects of OPA but does not evaluate what has been termed "biological" or "causal" interaction in the sense of departure from additivity in the joint effects. Therefore, we also calculated the relative excess risk due to interaction (RERI) on an additive scale. A positive value for RERI $>0$ indicates that the combined effect of OPA and IHD is greater than the sum of their separate effects assuming monotonic effects of both exposures $(56,57)$. Finally, we present analyses stratified by baseline IHD as a preferred alternative to the interaction models in order to allow for a more comprehensive account for covariate distributions that differed between IHD subgroups. 
Table 1. Characteristics of the study population and distribution of independent variables by ischemic heart disease (IHD) status at baseline

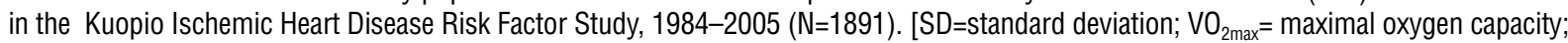
$\mathrm{VO}_{2 \text { res }}=$ percent oxygen uptake reserve; LDL=low-density lipoprotein; HDL=high-density lipoprotein; LTPA=leisure-time physical activity.]

\begin{tabular}{|c|c|c|c|c|c|c|c|c|c|}
\hline \multirow[t]{2}{*}{ Independent variables } & \multicolumn{4}{|c|}{ Men without IHD ( $N=1565)$} & \multicolumn{4}{|c|}{ Men with IHD (N=326) } & \multirow{2}{*}{$\frac{\text { Difference }}{\text { P-value a }}$} \\
\hline & $\mathrm{N}$ & Mean & $\%$ & SD & $\mathrm{N}$ & Mean & $\%$ & SD & \\
\hline \multicolumn{10}{|l|}{ Occupational physical activitiy measures } \\
\hline $\begin{array}{l}\text { Absolute energy expenditure per typical } \\
\text { workday at baseline (kcal) }\end{array}$ & 2078 & & & 875 & 2272 & & & 970 & 0.001 \\
\hline Relative aerobic strain $\left(\% \mathrm{VO}_{2 \max }\right)$ & & 29.7 & & 12.1 & & 38.5 & & 16.5 & 0.001 \\
\hline Reserve oxygen uptake $\left(\% \mathrm{VO}_{2 \text { res }}\right)$ & & 22.6 & & 13.5 & & 31.5 & & 19.2 & 0.001 \\
\hline \multicolumn{10}{|l|}{ Covariates } \\
\hline \multicolumn{10}{|l|}{ Age and technical factors } \\
\hline Age (years) & & 51.5 & & 5.1 & & 53.5 & & 3.9 & 0.001 \\
\hline $\begin{array}{l}\text { Participant in placebo group of lipid } \\
\text { lowering drug trial }\end{array}$ & 135 & & 8.6 & & 28 & & 8.6 & & 0.983 \\
\hline $\begin{array}{l}\text { Participant in treatment group of lipid } \\
\text { lowering drug trial }\end{array}$ & 136 & & 8.7 & & 27 & & 8.3 & & 0.811 \\
\hline \multicolumn{10}{|l|}{ Biological factors } \\
\hline Blood glucose $(\mathrm{mmol} / \mathrm{l})$ & & 4.70 & & 0.91 & 4.88 & & & 1.39 & 0.029 \\
\hline Plasma fibrinogen $(\mathrm{g} / \mathrm{l})$ & & 2.95 & & 0.52 & & 3.10 & & 0.58 & 0.001 \\
\hline Body mass index & & 26.7 & & 3.4 & & 27.1 & & 3.8 & 0.029 \\
\hline LDL-cholesterol (mmol/l) & & 3.99 & & 0.97 & & 4.17 & & 1.07 & 0.003 \\
\hline $\mathrm{HDL}$-cholesterol $(\mathrm{mmol} / \mathrm{l})$ & & 1.31 & & 0.29 & & 1.28 & & 0.32 & 0.114 \\
\hline Systolic blood pressure & & 133.9 & & 16.0 & & 133.0 & & 18.3 & 0.429 \\
\hline Lipid-lowering medication (yes) & 4 & & 0.3 & & 4 & & 1.2 & & 0.014 \\
\hline Anti-hypertensive medication (yes) & 179 & & 11.4 & & 115 & & 35.3 & & 0.001 \\
\hline \multicolumn{10}{|l|}{ Behavioral factors } \\
\hline Alcohol consumption (g/week) & & 71.5 & & 111.9 & & 88.3 & & 196.4 & 0.134 \\
\hline Smoking (cigarettes/day xyears & 142 & & & 290 & 210 & & & 348 & 0.001 \\
\hline Conditioning LTPA (hours/year) & 91 & & & 102 & 95 & & & 126 & 0.613 \\
\hline $\begin{array}{l}\text { Cardiorespiratory fitness }\left(\mathrm{VO}_{2 \max } \text { in } \mathrm{ml} \mathrm{O}_{2}\right. \\
\left.\times \mathrm{min}^{-1} \times \mathrm{kg}^{-1}\right)\end{array}$ & & 32.8 & & 7.0 & & 27.5 & & 6.9 & 0.001 \\
\hline \multicolumn{10}{|l|}{ Socioeconomic status } \\
\hline $\begin{array}{l}\text { Personal income (1000 FIM/year) } \\
\text { Psychosocial job factors }\end{array}$ & & 92.6 & & 56.7 & & 72.3 & & 37.4 & 0.001 \\
\hline Social support score at work (range $0-12$ ) & & 6.5 & & 2.5 & & 6.5 & & 2.4 & 0.882 \\
\hline Mental strain at work index (range $0-37$ ) & & 11.5 & & 6.3 & & 13.4 & & 7.1 & 0.001 \\
\hline Stress from work deadlines (yes) & 357 & & 23 & & 105 & & 32 & & 0.001 \\
\hline
\end{tabular}

a Student t-test or chi test.

The estimated relative HR can be interpreted as the approximate instantaneous relative risks associated with a particular risk factor. The proportional hazard regression model is advantageous compared to logistic regression models or direct calculation of relative risks because it utilizes information about time-to-AMI event to provide an estimate of the average instantaneous relative risk (ie, the relative hazard or ratio of incidence rates) over short time intervals in which the outcome remains a rare event even for older groups. We calculated HR and associated $95 \%$ CI. We also calculated absolute risk differences in terms of extra incident cases per person-time for both IHD subgroups taking the higher a priori risk for AMI among men with IHD into account. All analyses were performed using the statistical software Stata, version 13.1 (StataCorp LP, College Station, TX).

\section{Results}

\section{Characteristics of the study population}

The average age in the study cohort was 51.8 years [standard deviation (SD) 5.0], with 309, 321, 1149, 112 at age $42,48,54$, and 60 , respectively. Conditioning LTPA averaged 92 hours (SD 106) per year, BMI $26.7 \mathrm{~kg} / \mathrm{m}^{2}$ (SD 3.5), alcohol consumption $74 \mathrm{~g}$ per week (SD 130), and $29 \%$ were current or former smokers. The distributions of independent variables by baseline IHD are listed in table 1. Compared to men without IHD at baseline, men with IHD were two years older, earned $22 \%$ less, smoked more, had higher levels of biological risk factors, were less fit, experienced more mental strain and stress from deadlines at work, and worked about 1.6 hours more per week. Men with IHD also expended more energy at work and experienced higher levels of RAS. 


\section{Incidence of AMI}

Among the 1891 study participants, 495 first-time incident AMI since baseline were recorded during an average of 19.56 years of follow-up (range 0.01-27.76) yielding a total person-time of 36991 years and a yearly incidence rate of $1.34 \% ; 353$ of these AMI were recorded among 1565 men without baseline IHD (yearly incidence $1.11 \%$ ) and 142 among 326 men with baseline IHD (yearly incidence $2.60 \%$ ).

\section{Comparison of model fit between linear and quadratic hazard functions.}

Hazard functions were modeled in linear (using the continuous variable of the OPA exposure measure) and quadratic form (adding a quadratic term of the continuous OPA variable). The quadratic function was explored because it may better reflect anticipated nonlinear increases in AMI risk with increasing levels of OPA. Model fit was compared by maximum likelihood ratio tests. Results of the respective Stata lrtest did not show any statistical improvement between fully adjusted linear and quadratic models (P-values of 0.77, 0.47, and 0.35 for kilocalories, RAS, and $\mathrm{VO}_{2 \text { res }}$, respectively).

\section{Interactions between baseline IHD and OPA}

For absolute EE, no statistical interactions with baseline IHD were observed. Some positive interactions were observed between IHD and RAS (RERI 0.07, 95\% CI $0.01-0.13, \mathrm{P}=0.019$ ) and $\% \mathrm{VO}_{2 \text { res }}$ (RERI $0.06,95 \% \mathrm{CI}$ $0.01-0.11, \mathrm{P}=0.018$ ) in fully adjusted linear hazard models indicating supra-additivity of OPA and IHD effects (see table 2). In fully adjusted quadratic hazard models, there appeared to be some small negative interactions between IHD and RAS and $\mathrm{VO}_{2 \text { res }}$ (see table 3 ).

\section{Associations between OPA and 20-year AMI incidence}

Table 2 summarizes results obtained from linear hazard models in Cox regression analyses. It shows HR with 95\% CI and P-values for each measure of OPA using eight different regression models: (i) unadjusted; (ii) age-adjusted; (iii) adjusted for all covariates listed in table 1 (except cardiorespiratory fitness which is already accounted for in the relative exposure measures); (iv) additionally adjusted for IHD; (v) adding an IHD $\times$ OPA interaction term to model 4; (vi) stratified by IHD without adjustments; (vii) stratified by IHD with age adjustment; and (viii) stratified by IHD with full adjustments as in model 3. Subgroup results are presented for men without and with IHD based on interaction model 5 and, alternatively based on stratified analyses (models 7 and 8).
Absolute EE per typical workday in units of $500 \mathrm{kcal} /$ day shows positive associations with AMI in crude and age-adjusted models in combined analyses of all men. However, in stratified analyses, the hazard appeared limited to men without IHD. Adjustment for all covariates attenuated the estimates.

Relative aerobic strain measured in $10 \%$ units was positively associated with AMI for all men in crude and ageand fully adjusted models (models 1-4), and, for both men with and without IHD, also in interaction model 5 and crude and age-adjusted stratified analyses (models 6-7). In fully adjusted stratified analyses (model 8), only men without IHD showed an association between RAS and AMI. Small interactions between RAS and baseline IHD were found on the additive scale (RERI 0.07, $95 \%$ CI $0.01-0.13, \mathrm{P}=0.019)$. The strongest association between OPA and AMI after adjustment for all covariates was observed among men without baseline IHD, with each $10 \%$ increase in RAS resulting in an $18 \%$ increased instantaneous risk of AMI (HR 1.18, 95\% CI $1.08-1.28, \mathrm{P}=0.001)$

Percent oxygen uptake reserve measured in $10 \%$ units was positively associated with AMI for all men in crude and age- and fully adjusted models (models 1-4), and, for both men with and without IHD, also in interaction model 5 and crude and age-adjusted stratified analyses (models 6-7). In fully adjusted stratified analyses, only men without IHD showed an association of $\mathrm{VO}_{2 \text { res }}$ with AMI (HR 1.15, 95\% CI 1.07-1.23, $\mathrm{P}=0.001$ ). Interactions between $\mathrm{VO}_{2 \text { res }}$ and baseline IHD were found on the additive scale (RERI $0.06,95 \%$ CI $0.01-0.11$, $\mathrm{P}=0.018$ ).

The strongest association between any measure of OPA and AMI after adjustment for all covariates was observed among men without baseline IHD, with each $10 \%$ increase in RAS resulting in an $18 \%$ increased instantaneous risk of AMI (HR 1.18, 95\% CI 1.08-1.28, $\mathrm{P}=0.001$ ).

Table 3 summarizes results obtained from quadratic hazard models in Cox regression analyses. It shows the HR with $95 \% \mathrm{CI}$ and P-values for each measure of OPA using the same eight different regression models used for linear exposure models (see table 2) but now with an additional quadratic OPA term added to all models plus an additional IHD $\times \mathrm{OPA} 2$ term added to the interaction models. To indicate this difference, linear models $1-8$ with added quadratic terms were renamed quadratic models A-H.

Absolute EE per typical workday in units of $500 \mathrm{kcal} /$ day shows positive associations with AMI in crude and age-adjusted models in combined analyses of all men, 
Table 2. Hazard ratios (HR) and 95\% confidence intervals (95\% Cl) based on linear hazard modeling of the associations between occupational physical activity (OPA) and 20-year incidence of acute myocardial infarction ( $N=495)$ for all men (N=1891), men without $(\mathrm{N}=1565)$ and men with $(\mathrm{N}=326)$ ischemic heart disease (IHD). Kuopio IHD Risk Factor Study, 1984-2006. [RERI=relative excess risk due to interaction.]

\begin{tabular}{|c|c|c|c|c|c|c|c|c|c|c|}
\hline \multirow[t]{2}{*}{ Linear hazard models } & \multirow{2}{*}{$\begin{array}{l}\text { IHD } \\
\text { subgroup } \\
\text { status }\end{array}$} & \multicolumn{3}{|c|}{$\begin{array}{l}\text { Absolute energy expenditure } \\
\text { (unit } 500 \mathrm{kcal} / \mathrm{day} \text { ) }\end{array}$} & \multicolumn{3}{|c|}{$\begin{array}{l}\text { Relative aerobic } \\
\text { strain (unit 10\%) }\end{array}$} & \multicolumn{3}{|c|}{$\begin{array}{l}\text { Percent oxygen uptake } \\
\text { reserve (unit 10\%) }\end{array}$} \\
\hline & & $\mathrm{HR}$ & $95 \% \mathrm{Cl}$ & P-value & $\mathrm{HR}$ & $95 \% \mathrm{Cl}$ & P-value & $\mathrm{HR}$ & $95 \% \mathrm{Cl}$ & P-value \\
\hline \multicolumn{11}{|l|}{ Analyses of all men } \\
\hline Model 1: Unadjusted & Combined & 1.07 & $1.02-1.12$ & 0.007 & 1.28 & $1.21-1.34$ & $0.001^{b}$ & 1.20 & $1.15-1.26$ & $0.001^{b}$ \\
\hline Model 2: Age-adjusted & Combined & 1.07 & $1.02-1.12$ & 0.007 & 1.24 & $1.18-1.31$ & $0.001^{b}$ & 1.18 & $1.13-1.24$ & $0.001^{\mathrm{b}}$ \\
\hline Model 3: Fully adjusted a & Combined & 1.01 & $0.96-1.07$ & 0.592 & 1.16 & $1.09-1.23$ & $0.001^{b}$ & 1.12 & $1.06-1.18$ & $0.001^{b}$ \\
\hline $\begin{array}{l}\text { Model 4: Model } 3 \text { plus } \\
\text { adjustment for IHD }\end{array}$ & Combined & 1.00 & $0.95-1.06$ & 0.882 & 1.13 & $1.06-1.20$ & $0.001^{b}$ & 1.10 & $1.04-1.16$ & $0.001^{b}$ \\
\hline \multicolumn{11}{|l|}{ Interaction analyses } \\
\hline $\begin{array}{l}\text { Model 5: Model } 4 \text { plus } \\
\text { OPAxIHD interaction }\end{array}$ & $\begin{array}{r}\text { No IHD } \\
\text { With IHD }\end{array}$ & $\begin{array}{l}1.01 \\
1.00\end{array}$ & $\begin{array}{l}0.96-1.08 \\
0.94-1.06\end{array}$ & $\begin{array}{l}0.635 \\
0.994\end{array}$ & $\begin{array}{l}1.15 \\
1.14\end{array}$ & $\begin{array}{l}1.07-1.25 \\
1.06-1.22\end{array}$ & $\begin{array}{l}0.000^{\mathrm{b}} \\
0.000^{\mathrm{b}}\end{array}$ & $\begin{array}{l}1.12 \\
1.11\end{array}$ & $\begin{array}{l}1.04-1.19 \\
1.04-1.18\end{array}$ & $\begin{array}{l}0.001^{\mathrm{b}} \\
0.001^{\mathrm{b}}\end{array}$ \\
\hline $\begin{array}{l}\text { Departure from multiplicativity } \\
(\mathrm{OPA} \times \mid \mathrm{HD})\end{array}$ & & 0.99 & $0.97-1.02$ & 0.461 & 0.99 & $0.96-1.01$ & 0.338 & 1.00 & $0.98-1.02$ & 0.924 \\
\hline Departure from additivity (RERI) c & & -0.01 & $-0.05-0.04$ & 0.793 & 0.07 & $0.01-0.13$ & $0.019 b$ & 0.06 & $0.01-0.11$ & $0.018^{b}$ \\
\hline \multicolumn{11}{|l|}{ Stratified analyses } \\
\hline \multirow[t]{2}{*}{ Model 6: Unadjusted } & No IHD & 1.07 & $1.02-1.14$ & 0.013 & 1.27 & $1.19-1.36$ & $0.001^{b}$ & 1.20 & $1.13-1.27$ & $0.001^{b}$ \\
\hline & With IHD & 0.99 & $0.91-1.08$ & 0.820 & 1.13 & $1.03-1.24$ & $0.011^{b}$ & 1.09 & $1.01-1.18$ & $0.032^{b}$ \\
\hline \multirow[t]{2}{*}{ Model 7: Age-adjusted } & No IHD & 1.08 & $1.02-1.14$ & 0.012 & 1.24 & $1.15-1.33$ & $0.001^{b}$ & 1.18 & $1.11-1.25$ & $0.001^{b}$ \\
\hline & With IHD & 0.99 & $0.91-1.09$ & 0.866 & 1.13 & $1.03-1.24$ & $0.013^{b}$ & 1.09 & $1.01-1.18$ & $0.033^{b}$ \\
\hline \multirow[t]{2}{*}{ Model 8: Fully adjusted a } & No IHD & 1.04 & $0.97-1.11$ & 0.252 & 1.18 & $1.08-1.28$ & $0.001^{b}$ & 1.15 & $1.07-1.23$ & $0.001^{b}$ \\
\hline & With IHD & 0.98 & $0.89-1.08$ & 0.711 & 1.08 & $0.98-1.20$ & 0.129 & 1.06 & $0.97-1.16$ & 0.187 \\
\hline
\end{tabular}

a $\mathrm{HR}$ adjusted for all covariates listed in table 1 except cardiorespiratory fitness $\left(\mathrm{VO}_{2 \max }\right)$.

b $\mathrm{P}<0.05$.

c RERI on an additive scale using the nlcom post-estimation command in Stata: Values of 0 signal no additive interaction, $>0$ positive interaction, $<0$ negative interaction, assuming monotonicity of effects of both exposures. Note: this row shows the beta-coefficients customarily used to determine interactions (and not the exponentiated values used in other rows to denote HR).

however, in stratified analyses, the hazard appeared limited to men without IHD. Adjustment for all covariates attenuated the results.

Relative aerobic strain and oxygen uptake reserve measured in $10 \%$ units were positively associated with AMI for all men in crude and age-and fully adjusted models (models A-D), in interaction model E, and, for men without IHD only, in all stratified analyses (models F-H). In fully adjusted stratified analyses, a $10 \%$ increase in RAS resulted in a $14 \%$ increase of instantaneous risk of AMI (HR 1.14, 95\% CI 1.03-1.26, $\mathrm{P}=0.010$ ) and a similar $10 \%$ increase in $\mathrm{VO}_{2 \text { res }}$ resulted in an $11 \%$ increase in the instantaneous risk of AMI (HR 1.11, 95\% CI 1.02-1.22, $\mathrm{P}=0.018$ ) among men without baseline IHD. Some interactions on the multiplicative scale were observed between baseline IHD and RAS and $\mathrm{VO}_{2 \text { res }}$.

\section{Absolute risk difference in incident AMI cases by IHD subgroup}

Relative hazards from fully adjusted stratified analyses were multiplied with incident rates among men with $(2.60 \%)$ and without $(1.11 \%)$ IHD to calculate the number of extra incident AMI cases due to OPA in each subgroups in cases per 100000 person-years. Based on HR estimated in the fully-adjusted linear model 8 , a 10 -unit (\%) increase in RAS is associated with an estimated extra 200 incident cases among men without IHD and 208 extra incident cases among men with IHD. The respective values from the fully adjusted quadratic model $\mathrm{H}$ are 155 cases for men without IHD and 104 cases for men with IHD per 100000 person years.

\section{Associations between other cardiovascular risk factors and AMI}

The following other potential cardiovascular risk factors showed independent effects for all men in the fully adjusted linear or quadratic hazard models that measured OPA as RAS or $\mathrm{VO}_{2 \text { res: }}$ age, baseline IHD, systolic blood pressure, anti-hypertensive medication, BMI, blood glucose, low-density lipoprotein cholesterol, cholesterollowering medication, mental stress, and smoking. Interestingly, no statistically significant effects were found in any of these models for other covariates including widely accepted CVD risk factors such as income, social support at work, alcohol, or LTPA (data not shown).

Alternative models adjusting for SES under varying definitions and specifications did not alter the results and conclusions (results are available from authors upon request). 
Table 3. Hazard ratios (HR) and $95 \%$ confidence intervals $(95 \% \mathrm{Cl})$ based on quadratic hazard modeling of the associations between occupational physical activity (OPA) and 20-year incidence of acute myocardial infarction (N=495) for all men (N=1891), men without $(\mathrm{N}=1565)$ and men with $(\mathrm{N}=326)$ ischemic heart disease (IHD). Kuopio IHD Risk Factor Study 1984-2006. [RERI=relative excess risk due to interaction.]

\begin{tabular}{|c|c|c|c|c|c|c|c|c|c|c|}
\hline \multirow[t]{2}{*}{ Quadratic hazard models } & \multirow{2}{*}{$\begin{array}{l}\text { IHD } \\
\text { subgroup } \\
\text { status }\end{array}$} & \multicolumn{3}{|c|}{$\begin{array}{l}\text { Absolute energy expenditure } \\
\text { (unit } 500 \mathrm{kcal} / \text { day) }\end{array}$} & \multicolumn{3}{|c|}{$\begin{array}{l}\text { Relative aerobic } \\
\text { strain (unit 10\%) }\end{array}$} & \multicolumn{3}{|c|}{$\begin{array}{l}\text { Percent oxygen uptake } \\
\text { reserve (unit 10\%) }\end{array}$} \\
\hline & & $\mathrm{HR}$ & $95 \% \mathrm{Cl}$ & P-value & $\mathrm{HR}$ & $95 \% \mathrm{Cl}$ & P-value & $\mathrm{HR}$ & $95 \% \mathrm{Cl}$ & P-value \\
\hline \multicolumn{11}{|l|}{ Analyses of all men } \\
\hline Model A: Unadjusted & Combined & 1.06 & $1.01-1.12$ & $0.022^{b}$ & 1.32 & $1.22-1.41$ & $0.001^{b}$ & 1.23 & $1.15-1.31$ & 0.001 \\
\hline Model B: Age-adjusted & Combined & 1.06 & $1.01-1.12$ & $0.019^{b}$ & 1.27 & $1.18-1.36$ & $0.001^{b}$ & 1.20 & $1.12-1.28$ & 0.001 \\
\hline Model C: Fully adjusted a & Combined & 1.01 & $0.95-1.07$ & 0.745 & 1.14 & $1.04-1.23$ & $0.003^{b}$ & 1.09 & $1.02-1.18$ & 0.017 \\
\hline $\begin{array}{l}\text { Model D: Model C plus } \\
\text { adjustment for IHD }\end{array}$ & Combined & 1.00 & $0.94-1.06$ & 0.994 & 1.10 & $1.01-1.20$ & $0.023^{b}$ & 1.07 & $0.99-1.15$ & 0.089 \\
\hline \multicolumn{11}{|l|}{ Interaction analyses } \\
\hline $\begin{array}{l}\text { Model E: Model D plus OPAxIHD } \\
\text { interaction term }\end{array}$ & $\begin{array}{l}\text { No IHD } \\
\text { With IHD }\end{array}$ & $\begin{array}{l}1.01 \\
0.99\end{array}$ & $\begin{array}{l}0.95-1.07 \\
0.93-1.06\end{array}$ & $\begin{array}{l}0.830 \\
0.808\end{array}$ & $\begin{array}{l}1.12 \\
1.09\end{array}$ & $\begin{array}{l}1.03-1.22 \\
1.00-1.19\end{array}$ & $\begin{array}{l}0.011^{\mathrm{b}} \\
0.041^{\mathrm{b}}\end{array}$ & $\begin{array}{l}1.08 \\
1.07\end{array}$ & $\begin{array}{l}1.00-1.17 \\
0.99-0.15\end{array}$ & $\begin{array}{l}0.051 \\
0.093\end{array}$ \\
\hline $\begin{array}{l}\text { Departure from multiplicativity } \\
\left(O P A \times\left|H D+O P A^{2} \times\right| H D\right)\end{array}$ & & 0.99 & $0.96-1.01$ & 0.316 & 0.98 & $0.95-1.00$ & 0.095 & 0.99 & $0.97-1.00$ & 0.157 \\
\hline Departure from additivity (RERI) c & & -0.02 & $-0.08-0.04$ & 0.517 & 0.04 & $-0.03-0.11$ & 0.270 & 0.03 & $-0.02-0.09$ & 0.265 \\
\hline \multicolumn{11}{|l|}{ Stratified analyses } \\
\hline \multirow[t]{2}{*}{ Model F: Unadjusted } & No IHD & 1.08 & $1.01-1.15$ & $0.017^{b}$ & 1.30 & $1.19-1.41$ & $0.001^{b}$ & 1.22 & $1.13-1.32$ & $0.001^{b}$ \\
\hline & With IHD & 0.95 & $0.86-1.05$ & 0.289 & 1.10 & $0.95-1.28$ & 0.213 & 1.05 & $0.92-1.20$ & 0.465 \\
\hline \multirow[t]{2}{*}{ Model G: Age-adjusted } & No IHD & 1.08 & $1.02-1.15$ & $0.014^{b}$ & 1.25 & $1.15-1.37$ & $0.000^{b}$ & 1.19 & $1.10-1.29$ & $0.001^{b}$ \\
\hline & With IHD & 0.95 & $0.86-1.05$ & 0.336 & 1.09 & $0.94-1.27$ & 0.268 & 1.05 & $0.92-1.19$ & 0.512 \\
\hline \multirow[t]{2}{*}{ Model H: Fully adjusted a } & No IHD & 1.04 & $0.97-1.11$ & 0.324 & 1.14 & $1.03-1.26$ & $0.010^{b}$ & 1.11 & $1.02-1.22$ & 0.018 \\
\hline & With IHD & 0.95 & $0.84-1.07$ & 0.370 & 1.04 & $0.88-1.23$ & 0.654 & 1.02 & $0.88-1.17$ & 0.833 \\
\hline
\end{tabular}

a $\mathrm{HR}$ adjusted for all covariates listed in table 1 except cardiorespiratory fitness $\left(\mathrm{VO}_{2 \max }\right)$.

b $\mathrm{P}<0.05$

' RERI on an additive scale using the nlcom post-estimation command in Stata: values of 0 signal no additive interaction, $>0$ positive interaction, $<0$ negative interaction, assuming monotonicity of effects of both exposures. Note: this row shows the beta-coefficients customarily used to determine interactions (and not the exponentiated values used in other rows to denote HR).

\section{Discussion}

Impact of model choice on estimates of OPA effects and interaction with baseline IHD

This study contrasts two basic hazard models (linear and quadratic, both on an exponential regression scale) and several alternative approaches to effect modification by baseline IHD (adjustment, interaction on both additive and multiplicative scales, and stratified analyses) in order to empirically examine the influence of model choice. These alternatives were explored in fully adjusted models that took 19 potentially confounding factors into account including virtually all established biological, behavioral, and psychosocial CVD risk factors. Additional adjustment for baseline IHD is problematic because it may itself be a result of (past) OPA exposure and could therefore constitute an over-adjustment leading to an underestimation of OPA effects. Or IHD might share unmeasured common causes with both OPA and AMI, thus making it a potential collider, which can introduce bias when conditioned on and be part of the confounding path between OPA and AMI when not controlled for. In this paper, we present both models without (models 3 and $\mathrm{C}$ ) and with (models 4 and $\mathrm{D}$ ) adjustment for IHD. As expected, additional adjustment for IHD attenuated the estimates.

Relative hazards estimated for IHD subgroups from fully adjusted analyses allowing for interaction with baseline IHD (models 5 and E) showed no subgroup difference while analyses stratified by IHD subgroup (models 8 and $\mathrm{H}$ ) indicated that higher relative physical workloads increase the relative hazard of AMI among men without baseline IHD more than among men with IHD. The following reason may account for this discrepancy: our data indicate different covariate distributions across IHD subgroups (see table 1) and the predictive power of covariates differed between IHD subgroups (data not shown) also pointing to differences in the covariate structure between subgroups. Stratified analyses fully allow for such a different covariate structure in each IHD subgroup and therefore we consider the results of stratified analyses more valid than the estimates derived from the interaction models. However, both effect estimates for the subgroup with IHD may be biased downwards due to health-based selection as discussed below.

In addition, it is important to note that the reported lower relative hazards among men with IHD led to similar absolute increments in AMI incidence and the estimated number of extra AMI cases per person-year. For 
example, in the fully adjusted stratified linear models 8 for OPA measured as RAS, the smaller relative hazard (1.08) among men with IHD actually causes a nearly identical (slightly higher) absolute increment in incidence AMI cases per year $(1.08 \times 2.60 \%-2.60 \%=0.208 \%$ ie, 208 extra AMI cases per 100,000 person-years) than the higher relative hazard (1.18) of men without IHD $(1.18 \times 1.11 \%-1.11 \%=0.200 \%$ ie, 200 extra AMI cases per 100000 person-years), due to the higher baseline risk in the subgroup with IHD. For comparison, this effect of a $10 \%$ unit increase in RAS is comparable in magnitude to an independent age effect of 1.1 or 1.7 years among men with or without IHD, respectively (also based on fully adjusted model 8).

Interaction effects were assessed both on a multiplicative and additive scale with results varying not only by scale, but also by type of OPA measure (absolute versus relative $\mathrm{EE}$ ), and the form of the hazard function (linear versus quadratic). Overall, results were consistent with the presence of interactions between relative EE measures and IHD. While all investigated models represent valid analytic approaches and have been used in previous research, the different covariate structure in the IHD subgroups, the presence of interaction between some measures of OPA and baseline IHD, and the need for the development of OPA recommendations that take baseline cardiovascular health status into account, together favor the multipronged two-step analytic strategy utilized in this study. First, combined analyses with models including OPAxIHD interaction terms are being used to test for the presence of interaction (on both additive and multiplicative scales) in the combined study sample. Second, stratified analyses by IHD subgroup with models not including such interaction terms are being used to estimate the effect sizes separately in each subsample.

This study demonstrates that the choice of analytic strategies can influence the assessment of AMI risk and such choices may be in part responsible for inconsistencies in the literature. A multipronged approach exploring alternative strategies for subgroup analyses and hazard modeling can increase confidence in results that appear to follow a consistent pattern across different modeling strategies.

\section{Improved exposure assessment and residual misclas- sification}

To our knowledge, this is the first prospective cohort study of OPA and incident AMI using both absolute and relative measures of $\mathrm{EE}$ at work as exposure variables. Only our previous study of 11-year progression of atherosclerosis in a subgroup of this cohort also used both absolute and relative EE measures (26). Our study demonstrates that only the superior relative workload measures that take individual worker fitness into account predict CVD incidence while the absolute measure of EE does not not (in fully adjusted models).. The detailed exposure assessment methods allowing for an analyses of continuous OPA measures also needs to be considered an important strength of this study. The majority of cohort studies in the literature used only crude categorical measures of OPA and the associated misclassification bias toward the null may have contributed to inconsistent results. In fact, we can demonstrate that the significant effects of RAS on AMI observed in our models with continuous exposure measures could not be detected and subgroup differences reversed direction - when we used a dichotomous exposure measure comparing the effects of RAS above and below the maximum recommended level of 33\% (in models fully adjusted for the same covariates as in models with continuous exposure measures; data not shown). Using instead four exposure categories around this recommended maximum level (again in fully adjusted models), however, produced a pattern of non-monotonically increased AMI risk among all men and men without IHD but not among men with IHD (data not shown). Specifically, among men without IHD, the strongest relative hazards were observed among those with aerobic strain levels between $23-33 \%$ (HR 1.43, 95\% CI 1.08-1.90, $\mathrm{P}=0.013$ ) and levels $>43 \%$ (HR 1.64, 95\% CI 1.15-2.33, $\mathrm{P}=0.006$ ) compared to those with aerobic strain levels $<23 \%$, while the effect estimate for men with levels between $33-43 \%$ was lower and instable (HR 1.14, 95\% CI 0.80-1.61, $\mathrm{P}=0.466$ ).

Residual exposure misclassification may still have occurred in our study because the type and duration of the work activities were based on self-report data rather than direct observations and also because the assessment of EE did not include upper-extremity work or the handling of external loads. Instead it was limited to the energetic costs of moving one's own body or maintaining one's body posture (sitting, standing, walking, and climbing stairs). Such activities may occur together with the use of hand-held equipment, material handling, carrying, lifting, and other demanding work activities not captured by our occupational interview. The relative amount of static work could thus not be determined. The ambient temperature was also not accounted for, and the average MET values assigned to work activities may also differ according to the individual body composition of fat and fat-free mass (58). However, we have no reason to believe that this residual exposure misclassification was differential and therefore we expect any bias to be directed towards the null hypothesis of no association between OPA and AMI. In other words, we consider our observed hazard estimates to be conservative. In fact, a recent study showed that heavy lifting increased CVD and mortality risks associated with OPA (31). On the other hand, the nearly exclusive focus on lower-extremity activities in the computation of $\mathrm{EE}$ at work increases the 
validity of our assessments of relative EE measures that were based on the use of bicycle ergometry tests utilizing lower-extremity activity for the determination of workers' maximum aerobic capacity $(59,60)$.

Due to lack of data on the amount of static work, we cannot determine if a prolonged elevated heart rate (mostly due to dynamic work) or excessive blood pressure and peak loading of the heart (mostly due to static work) are primarily responsible for the observed positive associations between OPA and AMI. This limitation is typical for large-scale population-based epidemiological studies because detailed ergonomic observations and physiological measurements (necessary to separately assess dynamic and static work components across study participants who are working in many different workplaces) have not yet been feasible.

The lack of repeat relative EE measures in our study needs also to be considered as a typical limitation in this research possibly adding to a conservative misclassification bias. Development of CHD leading to AMI is itself a long-term process related to a complex and linked series of variables that may accumulate over the course of an individual's life (61). There is limited evidence to support the assumption that some risk factors are fixed and do not alter, even over long periods of follow-up (62). In our cohort, several indicators of OPA including occupational title, job, and repeat absolute EE measures all have been found to be rather stable over time (26). For example, repeat absolute EE measures were available at 4- and 11years follow-up, and these repeat measures were highly correlated (correlation coefficient 0.80 for 4 - and 0.64 for 11-year EE in kcal/day) thus limiting the extent of possible exposure misclassification. In our previous analyses of 11-year progression of carotid atherosclerosis in this cohort, we found consistently stronger associations with baseline relative EE measures compared to any cumulative absolute EE measures (26). In addition, work physiology and ergonomic principles predict that it is often not a high absolute amount of EE alone but rather a misfit between high job-related energy demands and low worker aerobic capacity that will lead to elevated blood pressure and heart rate during work, which constitute the central causal pathway according to Glagov et al's hemodynamic theory of atherosclerosis (63). For these reasons, we chose to focus on relative EE measures that were only available at baseline and to use only one baseline absolute EE measure in this analysis to allow comparisons between the predictive strengths of these measures. Again, any remaining exposure measurement error most likely introduced a conservative bias in effect estimation.

\section{Confounding control and possible over-adjustment}

The comprehensive adjustment for 19 potential confounders, including virtually all widely accepted bio- logical, behavioral, and psychosocial risk factors, needs to be considered an important strength of this study. Specifically, there are only few studies of OPA controlling for LTPA. LTPA and some other variables could be considered both as confounders and pathway variables, thus adjustment for them could constitute a partial over-adjustment. We also controlled for SES by personal income. Alternative models adjusting for SES under varying definitions and specifications did not alter the results and conclusions (results are available from authors upon request). This could be considered an over-adjustment since most physically demanding blue-collar jobs typically generate lower income than less physically demanding white-collar jobs. However, adjusting for all 19 covariates best reflected our goal to minimize any residual confounding, even if it resulted in some over-adjustment, more conservative effect estimates, and reduction of statistical power. The list of potential confounders was also predetermined by our intent to compare results from this study of symptomatic AMI with results from our previous study of nonsymptomatic atherosclerotic changes in the same study population. In contrast to that previous study where control for these confounders changed the effects only minimally, this study showed more substantial effect attenuation, especially among men without IHD.

\section{Comparisons with previous study of progression of atherosclerosis: healthy worker effect}

An apparent weaker association of OPA among men with versus without IHD (in relative terms only, see above) needs to be interpreted with caution. In light of the opposite findings in our previous study on progression of non-symptomatic atherosclerosis in the same study population, our current findings for symptomatic AMI need to be considered due to a health-based selection effect of men who survived in physical demanding jobs despite their IHD. Comparisons with our previous studies are facilitated by the use of the same OPA measures and multivariate models fully adjusting for the same set of potential confounders that were previously used in our study on 11-year progression of carotid atherosclerosis in this study population (26). An alternative OPA measure of static work posture (prolonged standing at work) also increased the risk of progression of asymptomatic atherosclerosis predominantly among the IHD subgroup $(26,64)$ indicating a greater vulnerability to higher workloads among men with IHD.

The consistent positive associations between relative $\mathrm{EE}$ and $\mathrm{AMI}$ are in line with previous research where both absolute and relative EE measures predicted 11-year progression of carotid atherosclerosis among men both with and without baseline IHD. However, in this study of AMI, only relative EE measures predicted an increased risk 
while absolute EE showed weaker or no effects depending on the analytic model. These diverging results within the same study sample and using the same measurements for all variables demonstrates that the choice of exposure assessment, analytic strategy, and symptomatic versus non-symptomatic CVD outcome can all be reasons for inconsistent findings in the literature.

\section{Observed associations between OPA and AMI: causal inference}

Associations between OPA and AMI were observed in analyses of all men but were stronger for men without than with IHD. Irrespective of the modulating influence of hazard modeling and analytic strategies described above, we think that the weaker association among men with IHD is probably due to health-based selection and therefore a biased estimate that needs to be balanced by contradictory findings from earlier studies of asymptomatic progression of atherosclerosis in this cohort that are less vulnerable to selection bias. One needs to consider that studies of mainly pre-clinical asymptomatic outcomes - such as progression of atherosclerosis measured as intima media thickening at a range with little if any organ perfusion consequences - tend to be less prone to outcome-driven health-based selection effects than studies with clinical symptomatic coronary artery disease outcomes, such as IHD and AMI. This is especially the case as these diseases often involve a history of painful symptoms (angina pectoris) that get triggered by strenuous physical activity, the exposure of interest. Workers with symptomatic IHD and related physical work limitations tend to leave physically demanding jobs during follow-up once symptoms occur, if they can, and thus are probably underrepresented in physically demanding jobs. It is noteworthy that the physical demands in terms of EE in $\mathrm{kcal} /$ day changed very little for this aging workforce over the first 11 years despite the fact that aerobic capacity declines steadily after the mid-twenties (26). Therefore high absolute EE at work can be expected to be associated with selected relatively heart-healthy individuals or individuals with IHD of lower severity. Such "healthy worker selection effects" plague studies of incident CVD and may also have contributed to inconsistent results in the literature.

Considering (i) both absolute and relative measures of OPA predicted progression of asymptomatic carotid atherosclerosis among both men with and without IHD in this cohort; (ii) relative EE was positively associated with AMI in this study, and (iii) the general notion that relative measures of OPA that take individual aerobic capacity into account better capture hemodynamic stressors associated with a discrepancy of aerobic fitness and EE demands at work, we believe that OPA increases the risk for AMI and possibly at different degrees for both men with and without IHD depending on their level of aerobic fitness. However, considering the evidence of a strong healthy worker effect and previous findings regarding progression of atherosclerosis in this cohort, the observed weaker relative OPA hazards among men with IHD may be spurious. They may be due to selection effects. Men with IHD may be instead also at an increased risk of AMI if exposed to above average EE at work, especially if their cardiorespiratory capacity does not meet these demands. Moreover, even lower relative hazards among men with IHD led to absolute incremental risk increases that are comparable to men without IHD.

Other researchers have found associations between OPA, aerobic fitness and clinical CVD outcomes (29). However this is the first study of OPA and incidence of AMI using individualized measures of the misfit between EE demands at work and aerobic capacity of the individual worker, while also combining persons with and without pre-existing IHD in interaction analyses. A recent study using a small sample of persons with pre-existing CVD suggested positive associations of high levels of OPA (and LTPA) with IHD incidence and mortality (65). Additional research is needed to reliably quantify risks or benefits related to OPA among the growing group of aging workers with existing IHD. Therefore, the exclusion of subjects with baseline IHD, which is still the predominant practice in CVD research, should be reexamined and replaced by investigations of both persons with and without baseline IHD while also carefully examining possible heterogeneity of the associations.

\section{The role of leisure-time physical activity}

OPA and LTPA may have opposing effects on health $(8$, 66). The reasons for this are not completely understood, however, in contrast to voluntary LTPA, which are typically self-paced and of lesser frequency or duration than OPA and allow for adequate rest, mandatory occupational activities of high frequency and duration are often paced by fixed work schedules, machines, coworkers, supervisors, or clients and may not allow for adequate rest periods. The need to work steady for many hours without exhausting themselves completely, and lack of time and facilities to change sweat-drained wet clothes may even prevent workers who can self-pace their work from engaging in sufficient short-term intense bouts of physical activity needed to achieve beneficial fitness training effects. In addition, dynamic activities such as walking may be beneficial at relatively low doses during leisure but may be detrimental at relatively high doses during work, especially if they occur in combination with other work activities, such as handling materials or holding tools involving considerable amounts of static work more likely to be detrimental for cardiovascular health.

In our study, conditioning LTPA had no independent 
effect in any of our models on AMI incidence (all HR 1.00 and $P$-values $\geq 0.9$ ) although previous analyses of this cohort had found a protective effect of this measure of LTPA on 4-year AMI risk (47). This contradictory finding may be explained by the fact that these previous analyses included non-working men and did not account for OPA. It also makes intuitive sense that $\mathrm{EE}$ at work, which on average was $2114 \mathrm{kcal} /$ day (ie, nearly six times as high as EE during LTPA of $382 \mathrm{kcal} /$ day) in this population and about 10 times as high as current recommended levels of LTPA (about $200 \mathrm{kcal} /$ week; see table D.3. in 67) would drive the association between overall physical activity and AMI. Others have reported that LTPA is only beneficial among those with sedentary jobs (14). In previous analyses of OPA and 11-year progression of atherosclerosis, we also found no independent effect of LTPA (26). However, a recent Belgian cohort study found detrimental effects of LTPA among persons with high levels of OPA (28) in contrast to previous reports on beneficial effects of LTPA possibly preventing detrimental effects of OPA $(68,69)$. These inconsistent findings warrant further exploration $(8,28)$. If more studies confirm the findings in the Finnish and Belgian cohorts, the current public health strategy to promote increases of LTPA may fail to reduce CVD among middle-aged manual workers exposed to relatively high physical job demands.

\section{Implications for prevention and medical practice}

Results of this representative population-based cohort study do not indicate that detrimental effects of OPA on AMI risk are limited to excessive RAS above the recommended maximum level of $33 \%$ but instead may occur at lower levels as well. It should be noted that traditionally recommended maximum levels of relative workloads were not based on epidemiological evidence but rather physiological measurements indicating change from aerobic to anaerobic metabolism. While recent epidemiological studies have shown that moderate and high levels of OPA are associated with an increased risk of CVD (32), this study more specifically shows that such detrimental effects may occur already at levels of OPA that are not only below average levels in this aging working population but also below currently recommended maximum levels for RAS. Additional epidemiological investigations with precise exposure assessments at work are needed to determine safe or potentially beneficial levels of OPA in terms of relative workload measures that take individual worker fitness into account.

Reductions of excessive relative aerobic workloads can in principal be achieved by three approaches, either alone or in combination: increase in aerobic fitness, increase in recovery time, and reduction of physical workload. Accordingly, some researchers have sug- gested interventions to increase cardiorespiratory fitness among workers to reduce CVD risks (70). However, for aging workers and workers with existing IHD or exercise-limiting musculoskeletal disorders or other comorbidities, fitness training may not be feasible or insufficient to meet work demands. While increased LTPA may be beneficial, especially for persons with low levels of OPA, for persons with high levels of OPA, resulting fatigue may be a barrier to LTPA. LTPA may actually increase CHD risk considerably as shown in a recent Belgian cohort study (28), although protective effects have also been reported $(68,69)$. A recent randomized workplace intervention trial showed that relatively few sessions of intensive aerobic exercise during paid work time increased fitness and reduced relative workloads among cleaners in Denmark but also led to significant increases in systolic blood pressure (71), a key risk factor for CVD. Primary prevention that is safe and does not rely on individual workers' behavioral changes, especially among older workers with high OPA levels, may need to address the discrepancy of individual cardiorespiratory fitness and physical job demands by reduction of physical job demands, daily or weekly work hours, and increases of recovery time $(72,73)$. While automation has reduced physical workloads over the last decades for skilled workers in some industries (eg, motor vehicle production), jobs in other industries often demand higher workloads (eg, in the growing healthcare, hospitality, and retail sectors). In some sectors the heaviest work is performed by lowwage immigrant workers who are underrepresented in national surveys and epidemiological studies (eg, custodial, construction, farm, and hotel and restaurant workers). General public health messages exclusively recommending increased physical activity may only be appropriate for the sedentary part of the working population and a subgroup of workers who participate in workplace health promotion programs. Those messages may not sufficiently address the still sizable working population performing heavy physical labor, the increasing proportion of aging workers with pre-existing chronic cardiovascular or musculoskeletal diseases or workers unlikely to receive an offer for or participate in workplace health promotion programs. In the absence of more controlled community-based intervention trials, it is difficult to compare the effectiveness of different approaches for primary CVD prevention.

The findings of our study confirm earlier research on possible detrimental effects of OPA at least for men without pre-existing IHD and point to a need for intervention research that is not limited to fitness-enhancing exercise alone but also includes interventions geared at the reduction of physical demands at work. Following the precautionary principle in public health protection, the study findings may already have important implications for the 
practice of occupational and rehabilitative medicine even in the absence of respective intervention trials. Primary CVD prevention efforts may benefit from a reduction of the energy demands in physically demanding jobs. Jobs in agriculture, forestry, commercial fishing, construction, manufacturing, warehousing, or retail are at especially high risk for leading to high aerobic strain. Secondary and tertiary prevention efforts may be indicated for persons who do not have a sitting desk job. Occupational medicine and other occupational health professionals can assist in an individualized approach using inexpensive ambulatory heart rate monitoring during work hours to determine the ergonomic fit between aerobic capacity and workload. Specifically, RAS or oxygen uptake reserve should be routinely assessed in non-desk workplaces during placement of new employees and in the process of designing work modifications for employees returning to work after being diagnosed with CHD. Both bicycle ergometry and ambulatory ECG may be warranted for workers with CVD (74).

Because it has been shown that $\mathrm{VO}_{2 \text { res }}$ is highly correlated with percent heart rate reserve $\left(\% \mathrm{HRR}=\left(\mathrm{HR}_{\text {work }}{ }^{-}\right.\right.$ $\left.\left.\mathrm{HR}_{\text {rest }}\right) /\left(\mathrm{HR}_{\max }-\mathrm{HR}_{\text {rest }}\right) \times 100 \%\right)$ across the aerobic fitness spectrum $(50,59)$, it is possible to estimate $\% \mathrm{HRR}(59)$, HR-estimated EE (HREEE) and $\mathrm{VO}_{2 \text { res }}$ using recently validated procedures (75) in combination with standard procedures estimating maximum heart rate based on resting heart rate and age (76) without the necessity to employ laboratory-based gas exchange analyses or bicycle ergometer tests.

It is best to use these relative measures of EE because they take individual differences of $\mathrm{VO}_{2 \max }$ into account; $\mathrm{VO}_{2 \max }$ has been found to differ markedly by gender, age, health status and other factors (77). Relative measures correlate better than absolute measures with actual cardiovascular workload, fatigue, heart rate elevations, and related health consequences of aerobic strain at work as shown by others (78) and for the first time for progression of atherosclerosis (26) and incidence of myocardial infarction (this paper) in this study population.

Intervention research needs to investigate the effectiveness and efficiency of possible interventions such as fitness-inducing exercise, increase of recovery time, and reduction of work hours and/or physical job demands, especially in the growing vulnerable population of aging workers with pre-existing CVD.

\section{Concluding remarks}

This study provides new evidence that increases of OPA in terms of relative aerobic workload $\left(\mathrm{VO}_{2 \max }\right.$ or $\mathrm{VO}_{2 \text { res }}$ ) predict an increased risk of AMI in middle-aged working men, even at levels of RAS that are below the recommended maximum. The findings further support the notion that inconsistencies in the literature on the cardiovascular health effects of OPA may be due to alternative choices of analytic strategies, if not exposure misclassification, health-based selection bias / healthy worker effect, uncontrolled confounding, and complex interactions between cardiovascular health status, cardiorespiratory fitness, and physical job demands in terms of EE at work. Primary prevention of CVD at the workplace requires approaches that take the individual worker health status, aerobic capacity, and the energy demands of the job into account. Different individuals may benefit from either an increase or a decrease of OPA or improvements in cardiorespiratory fitness.

\section{Acknowledgments}

This research was partially funded by the Finnish Academy of Science through the University of Eastern Finland. The authors thank Kimmo Ronkainen for managing and updating of underlying KIHD and national registry databases and provision of background information regarding respective study variables. The authors also thank cardiologist Jari Laukkanen for providing expert validation of AMI diagnosis by checking national hospital discharge registry data with other available hospital records including ECG and laboratory data.

\section{References}

1. Brownson RC, Boehmer TK, Luke DA. Declining rates of physical activity in the United States: what are the contributors? Annu Rev Public Health. 2005;26:421-43. http://dx.doi. org/10.1146/annurev.publhealth.26.021304.144437.

2. Rho HJ. Hard work? Patterns in physically demanding labor among older workers. Center for Economic and Policy Research: Washington, DC. 2010; p. 1-17.

3. U.S. Department of Health and Human Services, Physical activity and health: a report of the Surgeon General. U.S. Department of Health and Human Services, Centers for Disease Control and Prevention, National Center for Chronic Disease Prevention and Health Promotion: Atlanta, Georgia. 1996; p. 259.

4. Powell KE, Thompson PD, Caspersen CJ, Kendrick JS. Physical activity and the incidence of coronary heart disease. Annu Rev Public Health. 1987;8:253-87. http://dx.doi. org/10.1146/annurev.pu.08.050187.001345.

5. Berlin JA and Colditz GA. A meta-analysis of physical activity in the prevention of coronary heart disease. Am J Epidemiol. 1990;132(4):612-28.

6. Lee IM, Paffenbarger RS, Jr., Hennekens CH. Physical activity, physical fitness and longevity. Aging Clin Exp Res. 1997;9(12):2-11. http://dx.doi.org/10.1007/BF03340123. 
7. Li J, Siegrist J. Physical activity and risk of cardiovascular disease-a meta-analysis of prospective cohort studies. Int $\mathrm{J}$ Environ Res Public Health. 2012;9(2):391-407. http://dx.doi. org/10.3390/ijerph9020391.

8. Krause N. Physical activity and cardiovascular mortality disentangling the roles of work, fitness, and leisure. Scand J Work Environ Health. 2010;36(5):349-55. http://dx.doi. org/10.5271/sjweh.3077.

9. Salonen JT, Puska P, Tuomilehto J. Physical activity and risk of myocardial infarction, cerebral stroke and death: a longitudinal study in Eastern Finland. Am J Epidemiol. 1982;115(4):52637.

10. Menotti A, Seccareccia F. Physical activity at work and job responsibility as risk factors for fatal coronary heart disease and other causes of death. J Epidemiol Community Health. 1985;39(4):325-9. http://dx.doi.org/10.1136/jech.39.4.325.

11. Seccareccia F, Menotti A. Physical activity, physical fitness and mortality in a sample of middle aged men followed-up 25 years. J Sports Med Phys Fitness. 1992;32(2):206-13.

12. Salonen JT, Slater JS, Tuomilehto J, Rauramaa R. Leisure time and occupational physical activity: risk of death from ischemic heart disease. Am J Epidemiol. 1988;127(1):87-94.

13. Lapidus L, Bengtsson C. Socioeconomic factors and physical activity in relation to cardiovascular disease and death. A 12 year follow up of participants in a population study of women in Gothenburg, Sweden. Br Heart J. 1986; 55(3):295-301. http://dx.doi.org/10.1136/hrt.55.3.295.

14. $\mathrm{Hu} \mathrm{G}$, Jousilahti $\mathrm{P}$, Borodulin $\mathrm{K}$, Barengo NC, Lakka TA, Nissinen A, Tuomilehto J. Occupational, commuting and leisure-time physical activity in relation to coronary heart disease among middle-aged Finnish men and women. Atherosclerosis. 2007;194(2):490-7. http://dx.doi. org/10.1016/j.atherosclerosis.2006.08.051.

15. Barengo NC, Hu G, Lakka TA, Pekkarinen H, Nissinen A, Tuomilehto J. Low physical activity as a predictor for total and cardiovascular disease mortality in middle-aged men and women in Finland. Eur Heart J. 2004;25(24):2204-11. http:// dx.doi.org/10.1016/j.ehj.2004.10.009.

16. Kannel WB, Belanger A, D’Agostino R, Israel I. Physical activity and physical demand on the job and risk of cardiovascular disease and death: the Framingham Study. Am Heart J. 1986;112(4):820-5. http://dx.doi.org/10.1016/00028703(86)90480-1.

17. Sobolski J, Kornitzer M, De Backer G, Dramaix M, Abramowicz M, Degre S, Denolin H. Protection against ischemic heart disease in the Belgian Physical Fitness Study: physical fitness rather than physical activity? Am J Epidemiol. 1987; 125(4):601-10.

18. Johansson S, Rosengren A, Tsipogianni A, Ulvenstam G, Wiklund I, Wilhelmsen L. Physical inactivity as a risk factor for primary and secondary coronary events in Goteborg, Sweden. Eur Heart J. 1988;9(Suppl L):8-19. http://dx.doi. org/10.1093/eurheartj/9.suppl_L.8.

19. Menotti A, Keys A, Blackburn H, Aravanis C, Dontas A, Fidanza F, et al. Twenty-year stroke mortality and prediction in twelve cohorts of the Seven Countries Study. Int J Epidemiol. 1990;19(2):309-15. http://dx.doi.org/10.1093/ije/19.2.309.

20. Haapanen N, Miilunpalo S, Vuori I, Oja P, Pasanen M. Characteristics of leisure time physical activity associated with decreased risk of premature all-cause and cardiovascular disease mortality in middle-aged men. Am J Epidemiol. 1996; 143(9):870-80. http://dx.doi.org/10.1093/oxfordjournals. aje.a008830.

21. Harmsen P, Rosengren A, Tsipogianni A, Wilhelmsen L. Risk factors for stroke in middle-aged men in Goteborg, Sweden. Stroke. 1990;21(2):223-9. http://dx.doi.org/10.1161/01. STR.21.2.223

22. Stender M, Hense HW, Doring A, Keil U. Physical activity at work and cardiovascular disease risk: results from the MONICA Augsburg study. Int J Epidemiol. 1993;22(4):64450. http://dx.doi.org/10.1093/ije/22.4.644.

23. Eaton CB, Medalie JH, Flocke SA, Zyzanski SJ, Yaari S, Goldbourt U. Self-reported physical activity predicts longterm coronary heart disease and all-cause mortalities. Twentyone-year follow-up of the Israeli Ischemic Heart Disease Study. Arch Fam Med. 1995;4(4):323-9. http://dx.doi. org/10.1001/archfami.4.4.323.

24. Kristal-Boneh E, Harari G, Melamed S, Froom P. Association of physical activity at work with mortality in Israeli industrial employees: the CORDIS study. J Occup Environ Med. 2000;42(2):127-35. http://dx.doi.org/10.1097/00043764200002000-00005.

25. Krause N, Lynch JW, Kaplan GA, Cohen RD, Salonen $\mathrm{R}$, Salonen JT. Standing at work and progression of carotid atherosclerosis. Scand J Work Environ Health. 2000;26(3):227-36. http://dx.doi.org/10.5271/sjweh.536.

26. Krause N, Brand RJ, Kaplan GA, Kauhanen J, Malla S, Tuomainen T, Salonen JT. Occupational physical activity, energy expenditure, and 11-year progression of carotid atherosclerosis. Scand J Work Environ Health. 2007;33(6):405-24. http://dx.doi.org/10.5271/sjweh.1171.

27. Holtermann A, Burr H, Hansen JV, Krause N, Sogaard K, Mortensen OS. Occupational physical activity and mortality among Danish workers. Int Arch Occup Environ Health. 2012;85(3):305-10. http://dx.doi.org/10.1007/s00420-0110668-x.

28. Clays E, De Bacquer D, Janssens H, De Clercq B, Casini A, Braeckman L, et al. The association between leisure time physical activity and coronary heart disease among men with different physical work demands: a prospective cohort study. Eur J Epidemiol. 2013;28(3):241-7. http://dx.doi. org/10.1007/s10654-013-9764-4.

29. Holtermann A, Mortensen OS, Burr H, Sogaard K, Gyntelberg F, Suadicani P. Physical demands at work, physical fitness, and 30-year ischaemic heart disease and all-cause mortality in the Copenhagen Male Study. Scand J Work Environ Health. 2010;36(6):466-72. http://dx.doi.org/10.5271/sjweh.3120.

30. Lopes C, Santos AC, Azevedo A, Maciel MJ, Barros H. Physical activity and risk of myocardial infarction after the fourth decade of life. Rev Port Cardiol. 2005;24(10):1191207. 
31. Petersen CB, Eriksen L, Tolstrup JS, Sogaard K, Gronbaek $\mathrm{M}$, Holtermann A. Occupational heavy lifting and risk of ischemic heart disease and all-cause mortality. BMC Public Health. 2012;12:1070. http://dx.doi.org/10.1186/1471-245812-1070.

32. Li J, Loerbroks A, Angerer P. Physical activity and risk of cardiovascular disease: what does the new epidemiological evidence show? Current Opinion in Cardiology. 2013;28(5):575-83. http://dx.doi.org/10.1097/ HCO.0b013e328364289c.

33. Kristensen TS. Cardiovascular diseases and the work environment: a critical review of the epidemiologic literature on nonchemical factors [review]. Scand J Work Environ Health. 1989;15:165-79. http://dx.doi.org/10.5271/ sjweh.1864.

34. Theorell T. The psycho-social environment, stress, and coronary heart disease, in Coronary heart disease epidemiology: from aetiology to public health, M Marmot and Elliott P, Editors. Oxford University Press: New York. 1992; p. 256-73.

35. Schnall $P$, Landsbergis $P$, Baker D. Job strain and cardiovascular disease. Ann Rev Public Health. 1994;15:381-411. http:// dx.doi.org/10.1146/annurev.pu.15.050194.002121.

36. Schnall PL, Belkic K, Landsbergis P, Baker D, editors. The workplace and cardiovascular disease. State of the Art Reviews in Occupational Medicine. Vol. 15. Hanley \& Belfus: Philadelphia. 2000; p. 334.

37. Lynch JW, Krause N, Kaplan GA, Cohen R, Salonen R, Salonen JT. Workplace demands, economic reward, and the progression of carotid atherosclerosis. Circulation. 1997;96(1):320-7. http://dx.doi.org/10.1161/01.CIR.96.1.302.

38. Salonen JT. Is there a continuing need for longitudinal epidemiologic research? The Kuopio Ischaemic Heart Disease Risk Factor Study. Ann Clin Res. 1988;20(1-2):46-50.

39. Lakka TA, Laukkanen JA, Rauramaa R, Salonen R, Lakka HM, Kaplan GA, Salonen JT. Cardiorespiratory fitness and the progression of carotid atherosclerosis in middleaged men. Ann Intern Med. 2001;134:12-20. http://dx.doi. org/10.7326/0003-4819-134-1-200101020-00008.

40. Lynch J, Krause N, Kaplan GA, Tuomilehto J, Salonen JT. Workplace conditions, socioeconomic status, and the risk of mortality and acute myocardial infarction: the Kuopio Ischemic Heart Disease Risk Factor Study. Am J Public Health. 1997;87(4):617-22. http://dx.doi.org/10.2105/ AJPH.87.4.617.

41. Rose GA, Blackburn H, and Gillum RF, Cardiovascular survey methods. World Health Organization: Geneva; 1982.

42. Tunstall-Pedoe H, Kuulasmaa K, Amouyel P, Arveiler D, Rajakangas AM, Pajak A. Myocardial infarction and coronary deaths in the World Health Organization MONICA Project. Registration procedures, event rates, and casefatality rates in 38 populations from 21 countries in four continents. Circulation. 1994;90(1):583-612. http://dx.doi. org/10.1161/01.CIR.90.1.583.

43. Lakka TA, Salonen JT. Intra-person variability of various physical activity assessments in the Kuopio Ischaemic Heart Disease Risk Factor Study. Int J Epidemiol. 1992;21(3):46772. http://dx.doi.org/10.1093/ije/21.3.467.

44. Manninen P, Heliövaara M, Riihimäki H, Suomaiainen O. Physical workload and the risk of severe knee osteoarthritis. Scand J Work Environ Health. 2002;28(1):25-32. http:// dx.doi.org/10.5271/sjweh.643.

45. Salonen JT, Lakka TA. Assessment of physical activity in population studies - validity and consistency of the methods in the Kuopio ischemic heart disease risk factor study. Scand J Sports Sci. 1987;9(3):89-95.

46. Ainsworth BE, Haskell WL, Leon AS, Jacobs DR, Jr., Montoye HJ, Sallis JF, Paffenbarger RS, Jr. Compendium of physical activities: classification of energy costs of human physical activities. Med Sci Sports Exerc. 1993;25(1):71-80. http://dx.doi.org/10.1249/00005768-199301000-00011.

47. Lakka T, Venäläinen JM, Rauramaa R, Salonen R, Tuomilehto J, Salonen JT. Relation of leisure-time physical activity and cardiorespiratory fitness to the risk of acute myocardial infarction. N Engl J Med. 1994;330:1549-54. http://dx.doi. org/10.1056/NEJM199406023302201.

48. Karpansalo M, Lakka T, Manninen P, Kauhanen J, Rauramaa R, Salonen JT. Cardiorespiratory fitness and risk of disability pension: a prospective population-based study in Finnish men. Occup Environ Med. 2003;60:765-9. http://dx.doi. org/10.1136/oem.60.10.765.

49. Jorgensen K. Permissible loads based on energy expenditure measurements. Ergonomics. 1985;28(1):365-9. http://dx.doi. org/10.1080/00140138508963145.

50. Howley ET. Type of activity: resistance, aerobic and leisure versus occupational physical activity. Med Sci Sports Exerc. 2001;33(6 Suppl):S364-9; discussion S419--0.

51. Astrand P-O, Rodahl K. Textbook of Work Physiology, Physiological Bases of Exercise. McGraw-Hill Book Company: New York. 1986; p. 756.

52. Lynch JW, Kaplan GA, Cohen RD, Tuomilehto J, Salonen JT. Do cardiovascular risk factors explain the relation between socioeconomic status, risk of all-cause mortality, cardiovascular mortality, and acute myocardial infarction? Am J Epidemiol. 1996;144(10):934-42. http://dx.doi. org/10.1093/oxfordjournals.aje.a008863.

53. Kauhanen J, Kaplan GA, Goldberg DE, Salonen R, Salonen JT. Pattern of alcohol drinking and progression of atherosclerosis. Arterioscler Thromb Vasc Biol. 1999;19(12):3001-6. http:// dx.doi.org/10.1161/01.ATV.19.12.3001.

54. Taylor HL, Jacobs DRJ, Schucker B, Knudsen J, Leon AS, Debacker G. A questionnaire for the assessment of leisure time physical activities. J Chronic Dis. 1978;31(12):741-55. http:// dx.doi.org/10.1016/0021-9681(78)90058-9.

55. Cox DR, Oakes D. Analysis of Survival Data. Monographs on statistics and applied probability. Vol. xiii. London; New York: Chapman \& Hall. 1984; p.201.

56. Rothman KJ, Greenland S, Lash TL. Modern epidemiology. 3rd ed. Philadelphia: Wolters Kluwer Health/Lippincott Williams \& Wilkins. 2008; p. 758. 
57. Richardson DB, Kaufman JS. Estimation of the Relative Excess Risk Due to Interaction and Associated Confidence Bounds. American Journal of Epidemiology. 2009;169(6):756-60. http://dx.doi.org/10.1093/aje/kwn411.

58. Byrne NM, Hills AP, Hunter GR, Weinsier RL, Schutz Y. Metabolic equivalent: one size does not fit all. J Appl Physiol. 2005;99(3):1112-9. http://dx.doi.org/10.1152/ japplphysiol.00023.2004.

59. Swain DP, Leutholtz BC. Heart rate reserve is equivalent to \%VO2 reserve, not to \%VO2max. Med Sci Sports Exerc. 1997;29(3):410-4. http://dx.doi.org/10.1097/00005768199703000-00018.

60. Aminoff T, Smolander J, Korhonen O, Louhevaara V. Prediction of acceptable physical work loads based on responses to prolonged arm and leg exercise. Ergonomics. 1998;41(1):10920. http://dx.doi.org/10.1080/001401398187350.

61. Kuh D, Ben-Shlomo Y. A life course approach to chronic disease epidemiology. New York: Oxford University Press; 1997.

62. Clarke R, Shipley M, Lewington S, Youngman L, Collins R, Marmot M, Peto R. Underestimation of risk associations due to regression dilution in long-term follow-up of prospective studies. Am J Epidemiol. 1999;150(4):341-53. http://dx.doi. org/10.1093/oxfordjournals.aje.a010013.

63. Glagov S, Giddens D, Ku D. Hemodynamics and atherosclerosis: insights and perspectives gained from studies of human arteries. Arch Pathol Lab Med. 1988; 112:1018-31.

64. Krause N, Brand RJ, Kaplan GA, Malla S, Salonen JT. Working Posture and 11-year Progression of Carotid Atherosclerosis. In 28th International Congress on Occupational Health. Milan, Italy; 2006.

65. Holtermann A, Mortensen OS, Burr H, Sogaard K, Gyntelberg F, Suadicani P. Fitness, work and leisure-time physical activity, and ischaemic heart disease and all-cause mortality among men with pre-existing cardiovascular disease. Scand J Work Environ Health. 2010;36(5):366-72. http://dx.doi. $\operatorname{org} / 10.5271 /$ sjweh.2914.

66. Holtermann A, Hansen JV, Burr H, Sogaard K, Sjogaard G. The health paradox of occupational and leisure-time physical activity. Br J Sports Med. 2012;46(4):291-5. http://dx.doi. org/10.1136/bjsm.2010.079582.

67. Committee PAGA. Physical Activity Guidelines for Advisory Committee. United States Department of Health and Human Services: Washington, DC; 2008.

68. Holtermann A, Mortensen OS, Burr H, Sogaard K, Gyntelberg F, Suadicani $P$. The interplay between physical activity at work and during leisure time - risk of ischemic heart disease and all-cause mortality in middle-aged Caucasian men. Scand J Work Environ Health. 2009;35(6):466-74. http://dx.doi. org/10.5271/sjweh.1357.
69. Holtermann A, Marott JL, Gyntelberg F, Sogaard K, Suadicani $\mathrm{P}$, Mortensen OS, et al. Occupational and leisure time physical activity: risk of all-cause mortality and myocardial infarction in the Copenhagen City Heart Study. A prospective cohort study. BMJ Open. 2012;2(1):e000556. http://dx.doi. org/10.1136/bmjopen-2011-000556.

70. Korshøj M, Krustrup P, Jørgensen MB, Prescott E, Hansen AM, Kristiansen J, et al. Cardiorespiratory fitness, cardiovascular workload and risk factors among cleaners; a cluster randomized worksite intervention. BMC Public Health. 2012;12:645-54. http://dx.doi.org/10.1186/1471-2458-12645.

71. Korshøj M, Lidegaard M, Skotte J, Krustrup P, Krause N, Søgaard K, Holtermann A. Does aerobic exercise improve or impair cardiorespiratory fitness and health among cleaners? A cluster randomized controlled trial. Scand J Work Environ Health. 2015;41(2):140-152. http://dx.doi.org/10.5271/ sjweh. 3475

72. Krause N, Brand R, Kauhanen J, Kaplan G, Syme S, Wong C, Salonen J. Work time and 11-year progression of carotid atherosclerosis in middle-aged Finnish men. Prev Chron Dis. 2009;6(1):1-20.

73. Wang A, Arah O, Kauhanen J, Krause N. Work Schedules and 11-year progression of carotid atherosclerosis in Finnish men. Am J Ind Med. 2014 Oct 27. [Epub ahead of print]. http:// dx.doi.org/10.1002/ajim.22388.

74. Haskell WL, Brachfeld N, Bruce RA, Davis PO, Dennis CA, Fox SM, et al. Task Force II: Determination of occupational working capacity in patients with ischemic heart disease. J Am Coll Cardiol. 1989;14(4):1025-34. http://dx.doi. org/10.1016/0735-1097(89)90485-3.

75. Garet M, Boudet G, Montaurier C, Vermorel M, Coudert J, Chamoux A. Estimating relative physical workload using heart rate monitoring: a validation by whole-body indirect calorimetry. Eur J Appl Physiol. 2005;94(1-2):46-53. http:// dx.doi.org/10.1007/s00421-004-1228-9.

76. Karvonen MJ, Kentala E, Mustala O. The effects of training on heart rate; a longitudinal study. Ann Med Exp Biol Fenn. 1957; 35(3):307-15.

77. Shvartz E, Reibold RC. Aerobic fitness norms for males and females aged 6 to 75 years: a review. Aviat Space Environ Med. 1990;61(1):3-11.

78. Wu HC, Wang MJ. Determining the maximum acceptable work duration for high-intensity work. Eur J Appl Physiol. 2001;85(3-4):339-44. http://dx.doi.org/10.1007/ s004210100453.

Received for publication: 19 June 2013 